\title{
Road Safety Challenges in Sub-Saharan Africa: The Case of Ghana
}

\author{
Stephen T. Odonkor $\mathbb{D}^{1}{ }^{1}$ Hugues Mitsotsou-Makanga, ${ }^{1}$ and Emmanuel Nene Dei ${ }^{2}$ \\ ${ }^{1}$ School of Public Service and Governance, Ghana Institute of Management and Public Administration, Accra, Ghana \\ ${ }^{2}$ National Blood Service, Accra, Ghana \\ Correspondence should be addressed to Stephen T. Odonkor; stodonkor@gimpa.edu.gh
}

Received 15 December 2019; Revised 27 August 2020; Accepted 29 August 2020; Published 10 September 2020

Academic Editor: Filomena Mauriello

Copyright ( 2020 Stephen T. Odonkor et al. This is an open access article distributed under the Creative Commons Attribution License, which permits unrestricted use, distribution, and reproduction in any medium, provided the original work is properly cited.

\begin{abstract}
The importance of road safety in the developmental agenda of a country cannot be overemphasized. It is essential for effective socioeconomic development. However, several countries in the developing world are confronted by several challenges relating to road safety, which are inadequately investigated. These challenges further aggravate the already heavily burdened health-care systems. The aim of this study is, therefore, to determine and analyse road safety issues in Ghana aimed at contributing to national policy development, stakeholder engagements, and public safety education campaigns on road traffic collision. A qualitative study by one-on-one interviews with individuals $(n=97)$ in road safety leadership positions was performed from November 2018 to February 2019. The interviews were audio-recorded and transcribed. Data analysis was conducted using a constant comparative methodology approach facilitated by Atlas.ti 8.0 software. Important road safety challenges that were identified by the respondents were categorized into six thematic areas, namely, institutional, executional, managerial and operational, attitudinal and behavioural, research, and financial and investment challenges. We recommend that the government and stakeholders alike should tackle these challenges by building a collaborative environment where everyone is involved in the process of developing and implementing strategies aimed at overcoming these challenges as they arise. There is also the need to address the epidemic carnage of road traffic injuries, many of which are preventable since they arise from human actions and inactions.
\end{abstract}

\section{Introduction}

Road safety is critical to the socioeconomic agenda of nations across the world. Concerns about road traffic collision have been on the front burner of many countries, particularly developing countries, where road safety issues are compounded not only by an increase in population [1] but also by inadequate road infrastructure and ineffective safety policies and transportation systems [2-4]. It is estimated that about 1.35 million people around the world are killed by road collision annually, with an additional 50 million people sustaining various degrees of injury or disability [5]. The socioeconomic effect of road traffic collision (RTC) is enormous. Road traffic crashes account for $1 \%, 1.5 \%$, and $2 \%$ of gross national products in developing countries, transition economies, and highly motorized countries, respectively [6]. The world-wide cost of road traffic collision is estimated to be US\$ 518 billion annually, and RTC and injuries globally are projected to rise by $65 \%$ between the year 2000 and 2020 [7]. However, in low- and middle-income economies, deaths resulting from RTC are projected to rise by $83 \%[7,8]$. Road traffic collision is generally classified as a human-induced disaster, which is on a very rapid increase, complex, and influenced by multidimensional factors $[9,10]$. Amongst all identified determinants and factors of RTC, human behaviours or actions appear to be the predominant factors [11].

About $90 \%$ of RTC cases and injuries occur in developing countries, and 12 countries in sub-Saharan Africa are listed in the top 20 RTC-prone countries for cases and casualties [12]. Increasing populations and booming socioeconomic growth activities coupled with a rise in the number of vehicle ownership in several sub-Saharan African nations account for the alarming rates of RTC [13]. The rate of death through RTC per every 100,000 people is highest in Africa with 24.1 deaths per a 100,000 population $[5,14]$. 
These alarming statistics advances the topic of adequate and effective road safety policies and transport systems, which have both social and economic implications for national and regional concerns.

Ghana, one of the most populous countries in the Western Africa region after Nigeria, has an estimated population of over 28.83 million [15]. Statistics indicate that six people die daily on Ghanaian roads due to road traffic collision, and over 230 million dollars are lost yearly due to collision pertaining to road, leading to approximately 1,600 deaths [16, 17]. In 2001, Ghana recorded 73 deaths per 1000 collision, making it the second highest road traffic collisionprone nation among six West African countries [18]. Statistics from the National Road Safety Commission shows that Ghana loses about 1.7 per cent of its Gross Domestic Product every year to road collision in addition to the loss of lives [19].

Even though the statistics indicate that road safety is a major problem in Ghana, studies to investigate and understand issues of RTC and associated factors have been insufficient. Meanwhile understanding the physiology of RTC is critical to policy formulations and directions, as well as a priority in any decision-making efforts related to public safety and welfare. The goal of this study is, therefore, to determine and analyse road safety issues in Ghana aimed at contributing to national policy development and reforms, stakeholder engagements, and public safety educational campaigns on RTC.

\section{Methods}

This study adopted a qualitative approach to produce exclusive responses by interviewing participants from four categories of people. The first category is officials working in Road and Highways Authorities and all related road agencies; the second category includes academics with indepth knowledge on road safety issues; the third category consists of members of the general population that drive vehicles; and the last category is made up of road pedestrians. It involved a detailed one-on-one interview. Purposeful sampling was used to select the four categories of participants. It was also ensured that participants were adequately represented along gender and age dimensions. The drivers include licensed commercial drivers who operate in major lorry stations in Accra. This group of drivers is frequent users of major roads across the capital. Additionally, private car owners regularly using different major roads to their place of work were included. A sample of ninety-seven (97) was considered for the research which consisted of 30 officials, 20 academics, 30 drivers, and 17 pedestrians. This will ensure an adequate representation of the population.

2.1. Data Collection. Structured interview questions were asked by researchers with in-depth experience and understanding in qualitative research and interviews. Each interview session lasted for an average of 45 minutes. Eight probed open-ended questions were included to ensure an in- depth response from the study participants (Table 1 ). The interviews were audio-taped and professionally transcribed and reviewed to guarantee accuracy. This qualitative method adopted facilitated the study to attain the intended objectives, allowing investigation of the diverse issues developed around the subject matter. Due to the exploratory nature of the study, a qualitative approach was employed.

2.2. Data Analysis. Data obtained from the study were analysed by professionals with extensive experiences in road safety. They also have leadership experiences or occupy leadership roles in road safety management. Analysis was executed in stages taking into consideration philosophies of established theories. The analysis also employed methodical techniques to produce in-depth information established in the opinions communicated by the study participants.

The study adopted the constant comparative technique [20], which is an investigative method where exact quotes are classified into vital concepts. As the recorded interviews were studied, there was a continuous comparison between the sections and formerly coded sections to ascertain whether the same concept was apparent. The definitions of codes were expanded or refined if the concept could not be classified within existing codes, as necessary to fit the concepts emerging from the data. Transcripts were coded to facilitate data organization and recovery. Qualitative analysis software (Atlas.ti 8.0, Scientific Software Development, Berlin, Germany) was adopted.

2.3. Respondents' Consent. The study participants were informed about the purpose of the study and that participation was entirely voluntary and refusal to participate would not impact on work. They were free to refuse to answer any question and were at liberty to withdraw from the study at any time. They were also assured of utmost confidentiality before, during, and at the end of the study with no identifiers, personal information, or name of their congregation. We obtained Ethical Clearance and Approval from the Ghana Institute of Management and Public Administration (GIMPA) Institutional Review Board.

\section{Results}

Figure 1 shows the safety issues and challenges observed from the study. They are grouped under six categories: institutional challenges, executional challenges, managerial and operational challenges, attitudinal and behavioral challenges, research challenges, and finally, financial and investment challenges. The following schematic sketch has been drafted to illustrate the different categories of challenges. Figure 1 provides a schematic sketch to illustrate the different categories of road safety challenges.

3.1. Institutional Challenges. Institutional challenges represent some of the major challenges the road sector faces across Ghana. These challenges are related to the good governance and managerial abilities of institutions to 
TABLE 1: Interview guide questions.

\begin{tabular}{|c|c|}
\hline No. & Questions \\
\hline 1 & In your opinion, what is the status of road safety in Accra? \\
\hline & Is road safety alarming in Accra? \\
\hline 2 & If yes, how is it different from the previous years? \\
\hline 3 & $\begin{array}{l}\text { Does Ghana have a proper road safety policy? (a) If yes, is it easily accessible? } \\
\text { (b) Is it operational at the national, regional, and district level? } \\
\text { (c) Are all the players involved to participate to its functional and operational governance? }\end{array}$ \\
\hline 4 & $\begin{array}{c}\text { In your opinion, what are the main factors that cause road traffic collision in Accra? (a) Does socioeconomic and demographic } \\
\text { characteristics contribute to road traffic collision? }\end{array}$ \\
\hline 5 & Does Accra have an adequate transport system or plan? \\
\hline 6 & In your opinion, is the general driving population educated and well-informed about road safety? (a) If no, how can it be achieved? \\
\hline 7 & What are the preventive measures that can be put in place to prevent and improve road traffic collision in Accra? \\
\hline 8 & As an individual in the society, do we have a role to play concerning road safety? \\
\hline
\end{tabular}

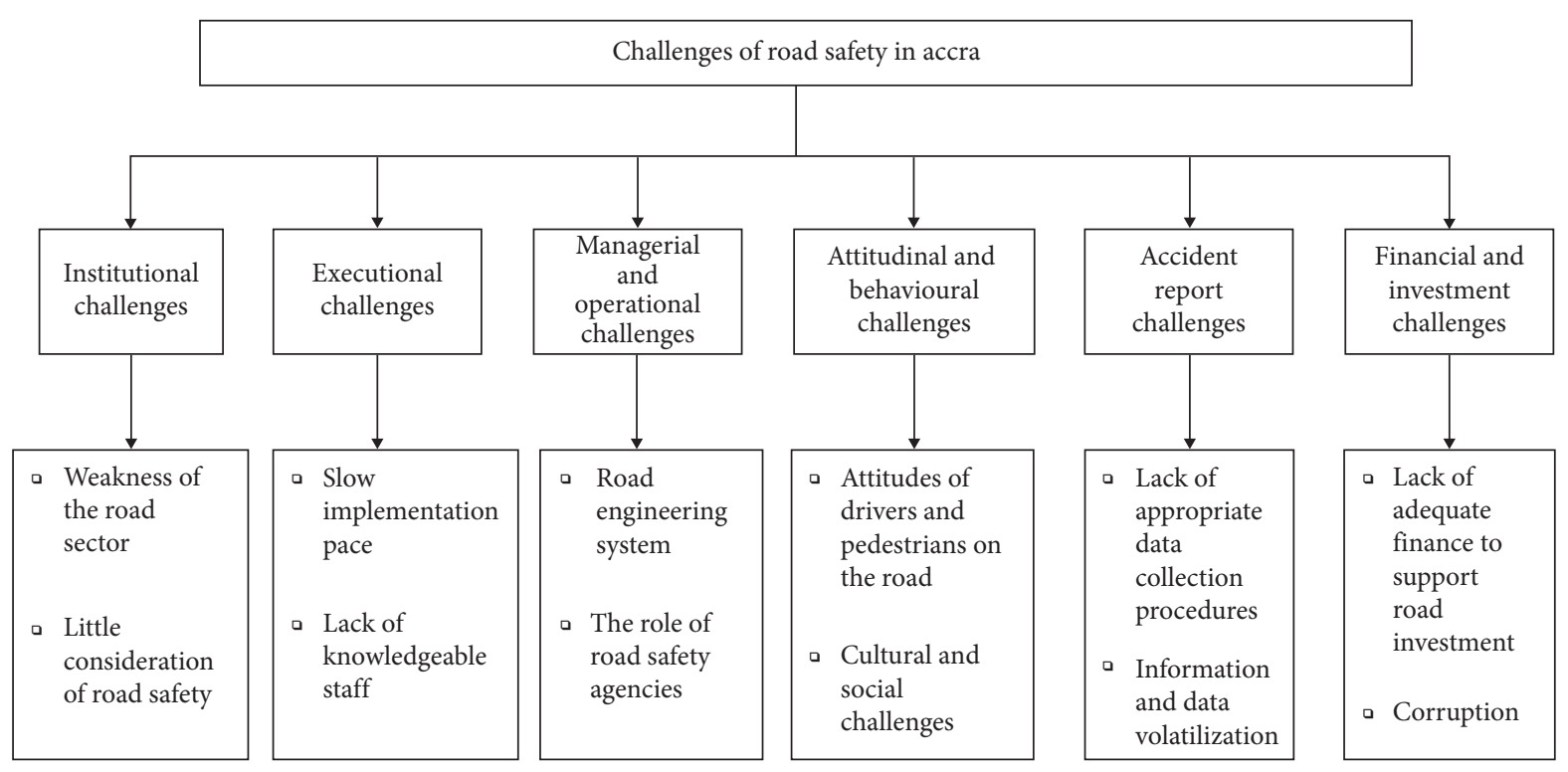

FIgURE 1: Challenges of road safety in Accra.

corporately manage the affairs of the country pertaining to road safety in Ghana. The road sector is perceived as weak and needs a lot of improvement and support, particularly from the government.

"In fact, the current institutions are not doing their intended work, or I may simply say, there is too much of laziness in the system, and this reflects in the way they operate. They need to enforce the laws at all levels"- an official (age $=33$ years).

"[.. .] Institutions in Ghana are not unified and solid, and I say so because they operate independently from one another, which is wrong. Let us take, for instance, the Ministry of Road and Highways; this office is right beside the Ministry Transport, and I can tell that they do not share the same documents, the same projects, and even more"- an official (age $=40$ years $)$.

The lack of coordination between and within institutions also contributes to and worsens the institutional challenges that are observed in the system. This challenge gives the impression that the government's concern about public safety is a mere political propaganda.

"The new government direction has nothing to offer in road safety, I mean no implementation that I have heard so far, no new reform [...]; it is ambiguous to think that it even cares much about all these road collisions going on"- an official (age $=45$ years).

3.2. Executional Challenges. The executional challenges from the research were identified as phase issues between the implementation of policies or reforms and their execution on the ground. The process is either always slow or nonexistent. Several factors have been identified as the causes of the slow implementation processes of policies and reforms. Some of these factors are purely monetary, and others are knowledge- and asset-based.

"The matter of road safety in Accra is basically implementation with coupled financial issues. Yes, there is a road safety policy; what I am saying is that it all has to do with 
money because whoever has to enforce this thing has to get the public aware. How many of you have heard on TV or radio station that, when crossing the road, you have to look left, look right [...]"- an official (age $=37$ years).

Another challenge identified is inadequate knowledge on road safety exhibited by official staff and officials assigned to road policy implementation. A significant number of the study participants alluded to the lack of appropriate knowledge on road safety among road agencies staff, policy makers, and lower level personnel such as traffic controllers who lack satisfactory knowledge on basic procedures with regards to road safety. An academic expressed this view:

"[...] the level of knowledge about road safety is lacking all across the country; the people of Ghana may have heard this expression one or two times, but in fact, are completely ignoring about what it really is and even me talking to you; I barely know what road safety entails and, if not, how to be safe in the road; that is all [...]"- an academic (age = 34 years).

The third challenge in this category is lack of supervision on the project based on road safety or other related works. It is seen and observed by all that most of the works pertaining to road present recurrent challenges that do have their place in today's discourse. These can be regarded as operational challenges and many have observed many obstacles on road, potholes, unfinished gutters, and uncompleted pedestrian bridges.

"We need to address the issue of monitoring and evaluation because if not it, what else again? We have, in Ghana, places where heaps of sand still stand on the road after or during ongoing works. Later on, it causes collision. Who are we to complain [...]?"- an academic (age $=41$ years).

\subsection{Managerial and Operational Challenges. Managerial and} operational challenges identified were based on engineering systems to regulate and supervise the road sector, including road signs and signals. Most of the issues raised were related to either the wrong interpretation of safety signs and signals or their wrong placement on the road. This presents an educational challenge to many road users and contributes to the inadequacy in training of officials that manage the road sector.

"I would say that the capital city of Ghana, which is Accra, does look developed, we are having four or five lanes on the road as compared to many African countries I have been to, and many signs as well. Even though, I know for sure that some of those drivers do not understand the majority of those safety signs [...]"- an official (age = 39 years).

Two of several observations related to operational challenges made by participants are indicated below:

"The National Road Safety Commission and the Road and Highway Authority both have policies that mainly have some in common, the prevention of road collision, and the adequate education of road users. I may not quote exactly what is in the policy or what the policy requires us to do. But, I am certain that we can find some principles, rules, and regulations governing the road sector at all levels"- an academic (age $=48$ years).

"[...] our road sector needs help; we know for sure we have a lot work to do. A lot of projects have been incomplete since last year. Also, a number of our institutions lose credibility because of one or two things we are unable to fix"- an official (age $=54$ years).

3.4. Attitudinal and Behavioural Challenges. Attitudinal and behavioural challenges are one of the most difficult setbacks of road safety because they involve the attitudes and beliefs of people and their way of life. Often than not, unsafe driving and inappropriate behaviours are rampant on the roads, and these are occasionally attributed to how most drivers think, behave, and act. Issues such as indiscipline on the road, overtaking, over speeding, encroachment, and lack of respect to traffic signs and signals are all challenges related to attitude.

"Some of the main factors that cause road collision is careless driving; there is so much carelessness on the road, and drivers play too much with our lives and speed up as they want despite the traffic signs. Even when they do so, no one question them, which is very wrong; at least, if the majority of them are questioned about their misconduct on the roads, and later on punished, some of them will surely seat up and adopt good conduct. Also, they do not know how to read or they are ignorant about safety signs and symbols on the roads. They may be aware, but they think they know it all"- a pedestrian (age $=33$ years).

Attitudinal and behavioural challenges need greater attention and seriousness. Public transport is used every single day, and each day represents a risk of a collision being caused by one of these factors including drunk driving, disregard for road rules and regulations, and insubordination to road officials. Statutory laws need to be enforced right from the acquisition of driving licenses to the accessibility of roads. Vehicles need to undergo the appropriate procedures and checks before being certified to be used on our roads.

"We need to take all the improper vehicles off the roads, and
also, we need to check for accurate driving license given to
some of those drivers. I seriously do not believe that because
someone can drive, he is reliable to do so and serve as a
qualified driver by transporting people. No, this task should
be given to a professional. So, there is a need to tackle all
these issues and set a very good atmosphere into the sys-
tem"- a pedestrian (age $=43$ years).

"Preventive measures are basically measures to put in place to prevent road collision; if the police were allowed to do their work, don't you think they will do this? I think it will go a long way to prevent road collision. The reason why I am saying this is, you know we are in a situation where you 
see the police being influenced by politics and politicians. Also, a politician may be on the road and the place where it is much chocked and he would have to force his way, and the policeman cannot do anything about it. These are the things which are being done in the clear view of the public, so tomorrow, if an ordinary person is doing it, would the policeman have the right to caution the person about it, no"- a pedestrian (age $=28$ years).

3.5. Collision Report Challenges. The challenges associated with collision reporting are numerous and contribute mostly to the depraved state of road safety records. Generally, collision reporting is considered as the most important element of road traffic collision which often leads to relevant key information about collision including how they occur and where and who were involved. It is a key component of finding a resolution to some of the challenges faced by the various authorities. Inadequate car collision reporting procedures, unqualified or inexperienced staff, outdated recording or car traffic collision data collection methods, unfinished reporting, and incomplete statement were observed as the major challenges.

"[...] after the collision has happened, this policeman was asking me questions about what I ate yesterday night. I told him that I am doing perfectly fine and he should carry on with the facts because, as a matter of fact, I am not at fault in this collision. Then, he asked one or two other questions, and that was all"- a driver (age $=48$ years).

"I assume that, in order to make an informed decision, collision reporting could play a vital role. Also, my question is, do we have a databank in which all collisions are reported and kept for future references and for evidence and support of collision prevention. The answer is no, and I say so because some of the methods used to collect data are just not right or, I should say, not adequate. In some reporting cases, we see with our eyes files that are left incomplete [...]"- an -official (56 years).

Collision reporting challenges promote information volatilization and contribute in a more significant manner to the economic expenditure of the country. If the necessary reforms are not put in place, more resources will be wasted to collision reporting efforts and preventive measures. There is a critical need to install recording systems and adopt the right procedures and modern method of identification and checklists for reporting collision.

"[.. .] most of the time a collision goes unnoticed, with no right and adequate procedures, and miscellaneous factors are high contributors of unstable data collection. At the end of the day, you realize that this crucial information does not add up, and because of that, they turn out to be unreliable and, therefore, thrown away or simply not picked in the whole process of collision reporting"- an official (age $=41$ years).

3.6. Financial and Investment Challenges. Financial and investment challenges were observed as another major issue in the road safety discussions. It is obligatory for a nation to construct, built, and invest in roads and to ensure its proper utilization and maintenance.

"We need road to move our businesses, and road is our only means of connection; as a trader, I move a lot, from Accra to Koforidua, and along the way, I also trade. Also, the road is good, even though, in some areas, there are some potholes, but it does not really affect my trading"- a driver (age $=36$ years).

"The 2019 project will be focused on some remote areas of Ghana; it basically focuses on improving road and transport in rural areas which present a number of difficulties up to date. But, despite this one (2019-project), quite a number of communities will be left out, and this will be for another long-awaited project"- an official (age $=51$ years).

Another problem which was identified by some respondents was corruption. They complained of excessive corruption in state institutions as the reason why some public projects are not implemented completely and effectively.

"[...] so today, you have to go through all these things; the question is how real is it, so then it becomes another area, and is the public administration really doing the right things or with just a bit of money, we talk, settled, and sorted out. On the face of it, looking at it from the outside, things have improved drastically, but for the reality, I do not know. What I am talking about is corruption throughout the system, and I do not want to mention any particular institution. The corruption runs throughout the system"- an academic (age $=54$ years).

\section{Discussion}

The goal of this study was to determine and analyse road safety issues in Ghana aimed at contributing to national policy development, stakeholder engagements, and public safety education campaigns on road traffic collision. Important road safety challenges that were observed from this study fell into six thematic areas, namely, institutional, executional, managerial and operational, attitudinal and behavioural, reporting, and financial and investment.

4.1. Institutional Challenges. The institutional challenges refer to the issues related to institutions and different authorities that control the road sector in Ghana. Several institutions govern the road sector in various ways and length. They do not only ensure safer roads but also implement rules, regulations, and policies that have law-abiding terms. These institutions work inclusively or exclusively together on the same objectives depending on the extent of their cooperation. Nevertheless, some issues are apparent and visible to all such as the lack of coordination between institutions and projects, shirking of responsibility and tasks, and untimely completion of a project and mismanagement of funds. Understanding 
and becoming aware of the abovementioned issues make it easier to tackle these institutional challenges.

4.1.1. Weakness in Road Safety Responsibilities. In Ghana, several ministries are responsible for road safety. The synchronization of the various aspects of the road safety mandate between these ministries and other government agencies seems to be problematic. There seems to be some disagreement between the ministries on which ministry bears the main responsibility of road safety. The Ministry of the Interior regulates road traffic within urban areas, controls road traffic, and intervenes in case of road collision through the Ghana Police Service, one of its subsidiary public sector organizations. The Ministry of Health is responsible for emergency services and medical care of the injured in hospitals, and the Ministry of Road Transport oversees maintenance of road infrastructure development.

The apparent difficulties in proper coordination and cooperation among these ministries do not help in ensuring road safety. Even though a lot of resources such as police patrol cars have been made available by the government in the recent months, more inputs are needed to realise the outcomes that will keep the roads safe.

4.1.2. Little Consideration of Road Safety. The number of ministries involved in the road safety work shows the many aspects of this field including engineering, education, enforcement, emergency medical services, and finances. Road safety is asserted to be one of the biggest problems in Ghana [16]. There is very little consideration being made to tackle the issue of road traffic collision in Accra. The two big cities in the country, Accra and Kumasi, record higher rates of road collision than other parts of the country, yet as revealed by Agyei-Boateng [21] and Andoh [22], the physical forces of motorized traffic are poorly controlled in these two cities. In the Northern and Western parts of the country, the potential growth in road collision caused by the increase in motor vehicles has been low because of the low density of vehicles and motorcycles. This situation makes it easier to resolve road traffic collision in rural and remote areas. Nonetheless, effective road safety programs need to be implemented and administered by state institutions, including road collision countermeasures as a form of preventive and proactive measures. Most administrative regions of the country have not been able to fully grab opportunities like those of the Greater Accra region, which undertake several activities on road safety.

4.2. Executional Challenges. Some challenges are identified in the implementation of different road safety regulations, policies, or even new reforms. It ought to be mentioned that several road safety works are currently on the verge of completion. However, based on evidence from the recent reports [23], majority of them are more likely to become "white elephants" or abandoned as uncompleted structures. This is obviously a challenge that needs to be tackled. Significant investment and assets are provided and vested into these solutions, which sometimes become irretrievable and affect largely the successful completion of projects. These executional issues are linked to gaps between the planned implementation of policies or reforms and their actual execution. In most cases, the process is slow and unenthusiastic. Several factors slow the implementation process including monetary, human, knowledge and training, and the lack of adequate resources.

4.2.1. Slow Implementation. Generally, the implementation of road safety policies takes an appreciable amount of time to be completed in Ghana [24]. Even in developed settings like North America and Western Europe, the implementation of road safety measures has taken time. The slow implementation pace of the road safety policy is further compounded by the lack of coordination between ministries, inadequate funding, inefficient civil services, and corruption, just to mention a few. It is observed that the issues are more related to management, economic, and social factors than to road safety problems. The knowledge of how to solve these problems seems to be considerably less developed than the knowledge on road collision counter measures [25]. Meanwhile, the basic problem is the lack of political concern and priority. Supposedly, with political concern, the other problems can be solved, at least, to some degree. The basic question then is "why is political concern for road safety low and how can this concern be increased." Allocations must be made for road safety issues and discourse; concerns need to be amplified; and barriers need to be broken to pave way for addressing the challenges.

4.2.2. Lack of Knowledgeable Staff. Knowledge about effective road safety measures is essential for reducing road collision. Some of the road safety officials already have the required knowledge and skills, and others need training. For the reduction of road collision to be sustainable, the people who work permanently in the road safety field must be nationals of the country. The ministries responsible for road safety seem to have highly qualified staff, and some of them have up-to-date knowledge on road safety work. Even though road safety training seems to be provided easily, the high turnover among the civil servants in this field is a problem. The management skills of the civil servants may also be another great problem. The evaluation of the road safety programs by the appropriate regulatory agencies and the training of managers as pointed out by the study participants is a key issue.

Our observations focus on the level of education of road users, government staff, and officials. Several studies have reported that the knowledge base on road safety signs and signals is low among the Ghanaian driving population, especially those engaged in commercial activities [13, 26, 27]. It is, in fact, a very critical issue to take with all seriousness because along the road route, road signs and symbols present a significant component of the road system. It is more than a priority for all road users to be well-versed in road safety signs, symbols, and regulations. This is, of course, one of the major prerequisites of obtaining license. 
4.3. Managerial and Operational Challenges. In ensuring a safe and adequate road system free from road traffic collision or having adequate measures in place that are well-maintained and supervised, it is critical to make sure that government structures execute the intended plans. Road agencies play a significant role in ushering the general driving population, pedestrians, and all road users into facilitated methods of preventing road collision.

4.3.1. Road Engineering System. Road planning and construction produce new roads and seem to be working well in all regions across the country. Foreign assistance is common in road planning in Ghana $[28,29]$. There is low prioritization of road safety planning as part of road construction projects [30], and this has significantly contributed to road accidents in Accra [18]. Standards and guidelines for road design are usually adapted from those of the home country of the expatriate experts. A report claims that although compromises are necessary for funding reasons, using international road safety standards and guidelines are not compromised [31]. Speed-reducing devices such as humps are used in most countries, especially close to schools. Road engineering measures such as roundabouts or speed humps generally reduce collision $[32,33]$. It is unknown whether they will have the same effect in developing countries as compared to highly motorized countries. It is evident that they are likely to do so because they influence physical forces or road user behavior directly. Most developing countries face challenges financing road maintenance, and road safety may be compromised. All regions in Ghana experience problems with theft and damage of road signs and the accompanying costs of replacing them. Recently, donors seem to be taking more interest in road maintenance, which is expected to make more room for road safety. Road maintenance including the improvement of black spots seems to be improving. This may be because of increased donor interest. Potholes are being covered and roads are being resurfaced than they used to be even though road maintenance is still inadequate. The significance given to road safety components of road planning, and maintenance seems to be the priority of the donors rather than that of the recipient countries.

4.3.2. The Role of Road Safety Agencies. Road safety agencies work together to coordinate all activities regarding safety on roads. In Ghana, they cooperate with the National Road Safety Commission to engage in several activities. Firstly, they are involved in the regulation of road traffic within rural and urban areas together with the police or military. Secondly, they intervene in road collision cases and provide health care services to victims. They are also involved in educating the populace on road and traffic safety issues. Additionally, with regards to road infrastructure, road safety agencies aid in planning and implementation of road constructions, as well as rehabilitation and maintenance of finished projects. Lastly, these agencies partake in organizing emergency services through the fire service and enforcing road traffic legislation through the police.
In all, both the National Road Safety Commission and the Ministry of Road and Highway have proven policies which aim to regulate, control, and safeguard the road and road users from all collision pertaining to the intended purpose and usage of roads. The abovementioned institutions have documented policies mainly used for road safety purposes. Policies controlling and governing the sector are present, but their implementation is still questionable. Notwithstanding, there are laws in place to regulate all issues and activities related to road safety in Ghana. Road agencies need not only to check the performance of vehicles and their accessibility on the road but also check the drivers and the different aspects of the road that will make driving life efficient and danger-free.

4.4. Attitudinal and Behavioural Challenges. Attitudinal and behavioural challenges of road safety vary with individuals, situations, places, or environment. These challenges are one of the most difficult aspects of road safety because they involve the attitude of people, their beliefs, and way of life. Often than not, unsafe driving and inappropriate behaviours are rampant on our roads, and these are attributed to how most drivers think, behave, and act. Issues such as indiscipline on the road, overtaking, overspeeding, encroachment, and lack of respect to traffic signs and signals are all challenges related to attitude.

4.4.1. Road Factors. Ghana's road network is expanding fast, and the road maintenance standard has started improving lately. However, there is still potential for improving the safety standards of roads such as the designing junctions, installing guardrails, marking spaces and crossings for pedestrians, and road lighting. Although road factors are rarely judged to be the main cause of collision because they are supposed to adjust their behavior to the road conditions, improved road safety standards often reduce the risk of road collision. Road construction and maintenance are being undertaken relatively better, but safety is not accorded high priority during such projects in most regions in Ghana.

4.5. Collision Report Challenges. The challenges linked to collision reporting are numerous, and they contribute most to the depraved state of road safety in Accra. Generally, collision reporting is the only one element, if not the most important part of road traffic collision which leads to relevant key information about how the collision happen and the details of the collision including where and who were involved. It is a key component of the resolution of some of the challenges faced by the various authorities. These challenges are because of ineffective car collision reporting procedures, unqualified or inexperienced staff, outdated method of recording or collecting car traffic collision data, incomplete reporting, and unfinished statement.

4.5.1. Lack of Appropriate Data Collection Procedures. Collision recording systems produce annual road collision statistics. Ghana has partly or fully computerized systems, 
and police data are used as the source in all regions. Some of the problems have been identified with the police sending collision reports to the central compiling unit in time. All injury collisions are included in the statistics because insurance requires a police report. In the previous years, a significant proportion of collision (27\%) was either not recorded or under-recorded [34]. This is a common problem in road collision statistics in Ghana [34].

4.5.2. Information and Data Volatilization. Unrecorded data can no longer be retrieved, and this situation results in the inadequate comprehension of trends related to car crashes or road traffic injuries. Information is a contributor to the huge expenditure, and resources towards research and the knowledge base on road safety. Therefore, it is more than a priority to implement a good and effective research centre where data collected from various road safety surveys will serve as a databank for future references. The research centre will use it as bedrock for research and evidence for the implementation of various policies.

4.6. Financial and Investment Challenges. Financial and investment challenges were observed as a last priority simply because they are some of the major issues that nations do not have any other preoccupations or excuses than to provide them solely for safeguarding the lives and welfare of its citizens. It is mandatory for a nation to construct, built, and invest in roads and to ensure their proper utilization and maintenance. Investing in roads and their maintenance is synonymous to guaranteeing the future because it is the main facilitator of all economic activities taking place in the country.

\section{Conclusions}

Findings from the present study revealed several road safety challenges in Ghana with regards to finance and investment, collision reports, attitudes and behaviours, management and operations, implementation and execution of road safety policies, and institutions. The challenges identified in the present study are crucial for policy formulation, as well as providing solutions in ensuring optimum road safety levels in Accra.

We recommend that government and stakeholders alike should tackle these challenges, by building a collaborative environment where everyone is involved in the process of developing and implementing strategies aimed at overcoming these challenges as they arise. There is also the need to address the epidemic carnage of road traffic collision, many of which are preventable since they arise from human actions and inactions.

5.1. Practical Application. Ministries, departments, and agencies that are directly involved or have responsibilities towards road safety need to restrategize in order to achieve their set objectives. Challenges confronting the road sectors in terms of safety ought to be confronted head on. There must also be the political will to correct altitudinal behaviours that have negatively impacted road safety. This also means sustainable and targeted road safety campaigns to ensure the safety of drivers and pedestrian alike.

5.2. Limitations. During the process of data collection and various interaction interviews, a lack of involvement and full-transparency amongst some of interviewees were apparent, and this may affect the findings of the study. The problem was largely observed from the government authorities and other related road safety agencies which were silent on the matter because of the fear of disclosing improper statistics. However, in order to minimize the effect of these observations on the study, the respondents were reassured of their confidentiality, and also, the interviews were conducted on a one-on-basis in a very conducive environment.

\section{Conflicts of Interest}

The authors declare that they have no conflicts of interest.

\section{References}

[1] M. Khanal and P. Sarkar, "Road safety in developing countries," Journal of Civil and Environmental Engineering, vol. 2, 2014.

[2] S. Heydari, A. Hickford, R. Mcllroy, J. Turner, and A. M. Bachani, "Road safety in low-income countries: state of knowledge and future directions," Sustainability, vol. 11, no. 22, p. 6249, 2019.

[3] N. Mittal, "Policies and programs for road safety in developing India," Journal of Emergencies, Trauma and Shock, vol. 1, p. 42, 2008.

[4] G. Evren and M. Akad, Transportation Planning Problems in Developing Countries, Technical University of Istanbul, Istanbul, Turkey, 2001.

[5] World Health Organization, Global Status Report on Road Safety 2018, World Health Organization, Geneva, Switzerland, 2018.

[6] G. Jacobs, A. Aeron-Thomas, and A. Astrop, Estimating Global Road Fatalities, Transport Research Laboratory (TRL), Crowthorne, UK, 2000.

[7] M. Peden, World Report on Road Traffic Injury Prevention, World Health Organization, Geneva, Switzerland, 2004.

[8] S. Gopalakrishnan, "A public health perspective of road traffic accidents," Journal of Family Medicine And Primary Care, vol. 1, no. 2, p. 144, 2012.

[9] M. H. Hosseinlou and M. Sohrabi, "Predicting and identifying traffic hot spots applying neuro-fuzzy systems in intercity roads," International Journal of Environmental Science \& Technology, vol. 6, no. 2, pp. 309-314, 2009.

[10] M. Sørensen and R. Elvik, Black Spot Management and Safety Analysis of Road Networks, Institute of Transport Economics, Oslo, Norway, 2007.

[11] A. Neelakantan, B. A. Kotwal, and M. Ilankumaran, "Determinants of injuries and road traffic accidents amongst service personnel in a large defence station," Medical Journal Armed Forces India, vol. 73, no. 3, pp. 216-221, 2017.

[12] World Health Organization, Violence, Injury Prevention, World Health Organization: Global Status Report on Road 
Safety 2013-Supporting a Decade of Action, World Health Organization, Geneva, Switzerland, 2013.

[13] N. A. Siaw, E. Duodu, and K. S. Sarkodie, "Trends in road traffic accidents in Ghana; implications for improving road user safety," International Journal of Humanities and Social Science Invention, vol. 2, no. 11, pp. 31-35, 2013.

[14] K. J. Balikuddembe, A. Ardalan, Z. D. Khorasani, A. Nejati, and M. S. Kasiima, "Road traffic incidents in Uganda: a systematic review study of five years trend," Journal of Injury and Violence Research, vol. 9, no. 1, 2016.

[15] The World Bank Group, Population of Ghana, The World Bank Group, Washington, DC, USA, 2019, https://data. worldbank.org/indicator/SP.POP.TOTL?locations=GH.

[16] A. Coleman, "Road traffic accidents in Ghana: a public health concern, and a call for action in Ghana, (and the sub-region)," Open Journal of Preventive Medicine, vol. 4, no. 11, p. 822, 2014.

[17] Ghana Business News, Ghana Loses over $\$ 230 m$ Every Year to Road Accidents, Ghana Business News, Accra, Ghana, 2010, https://web.archive.org/web/20100525120444/http://www. ghanabusinessnews.com/2010/05/21/ghana-loses-over-230mevery-year-to-road-accidents/.

[18] E. Mends Brew, J. Dadzie, B. A. Dadson, and M. O. Amoamah, "Modelling the trend of road traffic accidents in Accra," Mathematical Modelling and Applications, vol. 3, no. 1, 2018.

[19] U. Sheriff, "Ghana losses 1.7 per cent GDP to road accidents," 2019, https://awakenewsonline.com/ghana-losses-1-7-percent-gdp-to-road-accidents/.

[20] B. G. Glaser, "The constant comparative method of qualitative analysis," Social Problems, vol. 12, no. 4, pp. 436-445, 1965.

[21] F. Agyei Boateng, Modeling Vehicle Traffic Flow between Traffic Light Nodes with Partial Differential Equations, Ph.D. thesis, Kwame Nkrumah University of Science and Technology, Kumasi, Ghana, 2013.

[22] A. K. Andoh, Managing Road Traffic Congestion in the Cape Coast Metropolis, Ph.D. thesis, University of Cape Coast, Cape Coast, Ghana, 2014.

[23] C. M. Damoah and K. Asamoah, "Public private partnerships for improved service delivery: the case of intercity STC coaches in Ghana," Development in Practice, vol. 2020, Article ID 1757623, 13 pages, 2020.

[24] C. T. Amoatey and A. N. Ankrah, "Exploring critical road project delay factors in Ghana," Journal of Facilities Management, vol. 15, no. 2, 2017.

[25] E. Janik, The Surprisingly Controversial History of Seat Belts, Wisconsin Public Radio, Madison, WI, USA, 2017, https:// www.wpr.org/surprisingly-controversial-history-seat-belts.

[26] S. A. Sasu-Mensah, Road traffic accidents on the accra-kumasitamale road corridor, Ph.D. thesis, University of Ghana, Accra, Ghana, 2015.

[27] L. A. Abimah, Assessing approaches to changing road safety behaviours of commercial drivers in ho municipality, Ph.D. thesis, University of Ghana, Accra, Ghana, 2013.

[28] J. Vondee-Awortwi, Aid as a catalyst to development?: the case of Ghana's political and economic transformation (1957-2013), Ph.D. thesis, Erasmus University Rotterdam, Rotterdam, Netherlands, 2017.

[29] P. F. Boakye, "Foreign aid and economic growth in Ghana (1970-2005)," Ph.D. thesis, Kumasi, Ghana.

[30] G. E. Gumah, Spatio-temporal analysis of road traffic accident on the Accra-tema motorway: causes and risk factors, Ph.D. thesis, University of Ghana, Accra, Ghana, 2015.

[31] M. G. Martinez and N. Poole, "The development of private fresh produce safety standards: implications for developing mediterranean exporting countries," Food Policy, vol. 29, no. 3, pp. 229-255, 2004.

[32] N. Pardon and C. Average, "The effectiveness of traffic calming measures in reducing road carnage in masvingo urban," International Journal, vol. 3, no. 2, pp. 2305-1493, 2013.

[33] R. A. Retting, S. A. Ferguson, and A. T. McCartt, "A review of evidence-based traffic engineering measures designed to reduce pedestrian-motor vehicle crashes," American Journal of Public Health, vol. 93, no. 9, pp. 1456-1463, 2003.

[34] M. Salifu and W. Ackaah, "Under-reporting of road traffic crash data in Ghana," International Journal Of Injury Control And Safety Promotion, vol. 19, no. 4, pp. 331-339, 2012. 